\title{
Regulating own and teammates' emotions prior to competition
}

\author{
Andrew Friesen ${ }^{1}$, Damian Stanley ${ }^{2}$, Tracey Devonport ${ }^{2}$, and Andrew M. Lane ${ }^{2, *}$ \\ ${ }^{1}$ Department of Kinesiology, The Pennsylvania State University, Berks Campus, 114B Beaver, P.O. Box 7009 Tulpehocken Rd, \\ Reading, PA 19610 610-396-6154, USA \\ ${ }^{2}$ Institute of Sport and Human Sciences, University of Wolverhampton, Gorway Road, Walsall, WS13BD, UK
}

Received 4 June 2018, Accepted 3 May 2019

\begin{abstract}
We examined intra- and interpersonal emotion regulation in the hour prior to athletic competition. Specifically, we investigated the extent to which differences between experienced and desired emotions were related to emotion regulation processes. Participants $(n=114)$ from team/doubles sport rated their experienced and desired emotions before a recent competition, and listed strategies used to regulate emotions reporting frequency, effectiveness, and self-efficacy for each strategy used. They followed the same procedure in relation to perceived emotions in a teammate. Results show athletes who experienced emotions close to their desired states reported significantly higher regulatory emotional self-efficacy than those further from their desired states. Further, their emotion regulation strategies were used more frequently and were more effective. Qualitative results indicated that participants attempted to regulate similar emotions in themselves and others, but used different strategies to accomplish these tasks to different degrees of frequency. The findings highlight the role of self-efficacy in emotion regulation; an individual difference variable which merits attention in future emotion regulation interventions.
\end{abstract}

Key words: emotion, mood, affect, self-regulation, psychological skills

Résumé-Réguler ses propres émotions et celles de ses coéquipiers avant la compétition. Nous avons examiné la régulation des émotions intra et interpersonnelles une heure avant la compétition sportive. Plus précisément, nous avons examiné dans quelle mesure les différences entre les émotions éprouvées et les émotions souhaitées étaient liées aux processus de régulation des émotions. Les participants $(n=114)$ de sports d'équipe ou de doubles ont évalué leurs émotions éprouvées et souhaitées avant une compétition récente et ont répertorié les stratégies utilisées pour réguler les émotions, la fréquence, l'efficacité et l'auto-efficacité de chaque rapport. Ils ont suivi la même procédure en ce qui concerne les émotions perçues chez un coéquipier. Les résultats montrent que les athlètes qui ont ressenti des émotions proches de l'état souhaité ont signalé une auto-efficacité émotionnelle régulatrice nettement plus élevée que ceux qui s'éloignaient de l'état souhaité. En outre, leurs stratégies de régulation des émotions ont été utilisées plus fréquemment et ont été plus efficaces. Les résultats qualitatifs indiquent que les participants ont tenté de réguler des émotions similaires chez eux et chez les autres, mais ont utilisé différentes stratégies pour accomplir ces tâches à différents degrés de fréquence. Les résultats soulignent le rôle de l'efficacité personnelle dans la régulation des émotions; une variable de différence individuelle qui mérite l'attention dans les futures interventions de régulation des émotions.

Mots clés : émotion, humeur, affect, autorégulation, compétences psychologiques

The relationship between affective states (e.g., emotions and mood) and sport performance is well established (Beedie, Terry, \& Lane, 2000; Craft, Magyar, Becker, \& Feltz, 2003; Jokela \& Hanin, 1999; Lane \& Terry, 2016). Researchers have found that athletes can identify optimal affective states and will attempt to regulate them accordingly (Hanin, 2010). The terms affect, mood and

\footnotetext{
*Corresponding author: a.m.lane2@wlv.ac.uk
}

emotion have sometimes been used interchangeably in research, however distinctions have been drawn between them. Emotions are typically more intense than mood, shorter lasting and arise in specific response to a situation, person, event, or object (see Barrett \& Russell, 1999; Lane \& Terry, 2016; Parkinson, Totterdell, Briner, \& Reynolds, 1996). Barrett \& Russell (1999) elucidated that core affect represents ever-present feeling states which comprise just one part of what they refer to as prototypical emotion 
episodes; these in turn are hypothesized to arise in response to specific situation or events and have cognitive, behavioral, feeling, and physiological elements. In their work, moods were distinguished from core affect purely in the sense that they last for a more prolonged period of time.

In the present study, we focus on affective experiences arising in relation to a specific competitive sports performance, and therefore, we use the term emotion. Research is clear, that athletes experience intense emotions and sometimes this is not how they would like to feel, and therefore, they use strategies to regulate emotions. The present study is concerned with how we regulate our own emotions and how they relate to the emotional experiences of others. Emotion regulation has been defined as the "process of initiating, avoiding, inhibiting, maintaining, or modulating the occurrence, form, intensity, or duration of internal feeling states, emotion-related physiological processes, emotion-related goals, and the behavioral concomitants of emotion, generally in the service of one's goals" (Eisenberg, Spinrad, \& Smith, 2004, p. 278). Emotion regulation sits within the broader theoretical framework of self-regulation, which suggests individuals attempt to reduce discrepancies between their current and desired emotional states (Carver \& Scheier, 1990). That is, people monitor how they are feeling contrasted against how they want to feel, and will seek to make adjustments if they recognize a discrepancy between these two states. For example, if an athlete believes that she should ideally feel energetic before competition, but actually feels somewhat sluggish, then this discrepancy between current and desired emotions will drive efforts to feel more energetic.

However, while past researchers have examined emotion regulation strategies in sport (e.g., Friesen, Devonport, \& Lane, 2016; Lane, Beedie, Jones, Uphill, \& Devonport, 2012; Stanley, Lane, Beedie, Friesen, \& Devonport, 2012), researchers have rarely examined the associated efforts involved with emotion regulation (e.g., self-efficacy, frequency of use, perceived effectiveness) as a function of the size of differences between desired and experienced emotions. Research has demonstrated that athletes have specific constellations of emotions they believe drive their best performance (see Hanin, 2007), and emotion regulation strategies should be centered on influencing the intensity or content of the emotions. Adopting this approach, Robazza, Pellizzari, \& Hanin (2004) found that helping athletes to regulate emotions they associated with their optimal past performance states resulted in improved performance. Hanin et al. (e.g., Hanin \& Stambulova, 2002) extended this work by showing idiosyncratic emotion content and intensity are different across situations (e.g., practices and competitions) and can vary across pre-, mid-, and post-performance situations. Therefore, consistent with self-regulation theory, rather than referencing past performances we opted to analyze emotion regulation activity as a function of the difference between one's experienced and desired emotions to examine whether a larger discrepancy between the two would be associated with different emotion regulation efforts.
A growing area in emotion research is recognition that the generation, expression, and regulation of emotions are inherently social (e.g., Van Kleef, Cheshin, Fischer, \& Schneider, 2016). Parkinson (1996) emphasized that the cause, effect and function of emotions are social in nature. This has clear implications for sport, which is fundamentally a social activity involving interactions between teammates, coaches, spectators, opponents, and referees (Friesen, et al., 2013). Athletes could try to influence the emotions of many different people in a sporting situation (e.g., trying to anger an opponent, console a teammate, or guilt an official), or might find their own emotions influenced by others. For example, one athlete might seek to share their emotions with another in order for both to feel better (e.g., Stanley, et al., 2012). Interpersonal emotion regulation being reported in studies on ice hockey (Friesen, Devonport, Sellars, \& Lane, 2015), curling (Tamminen \& Crocker, 2013), cricket (Totterdell, 2000), baseball (Cheshin, Heerdink, Kossakowski, \& Van Kleef, 2016), soccer (Moll, Jordet, \& Pepping, 2010), rugby (Campo, et al., 2016), lacrosse (Friesen et al., 2016), volleyball (Palmateer \& Tamminen, 2018), and running (Stanley, et al., 2012). We therefore recommend that research in sport should consider both intra- and interpersonal approaches to emotion regulation (cf. Friesen, et al., 2016; Stanley, et al., 2012).

Consistent with many other skills, people differ in their emotion regulation capacities and skills usage (Meyer \& Fletcher, 2007; Petrides, Furnham, \& Mavroveli, 2007). People not only use different strategies, but also vary in their own confidence to apply them. Furthermore, some strategies might be more or less effective than others (Petrides, et al., 2007). Regulatory emotional self-efficacy (i.e., one's belief about their capability to regulate their emotions) has been identified as influential in this relationship (Alessandri, Vecchione, \& Caprara, 2015). In a longitudinal study monitoring emotional and social experiences across a major life transition (i.e., before going to college through to the end of the freshman year), regulatory emotional self-efficacy partially mediated the effects of beliefs regarding the controllability of emotions on emotional outcomes (Tamir, John, Srivastava, \& Gross, 2007). Totterdell \& Leach (2001) found higher expectations of being able to regulate unpleasant emotions were associated with higher happiness ratings and players' batting averages in cricket. This suggests that beliefs about emotion regulation ability influence the unfolding process of emotional changes before and during competition. Enhancing understandings of regulatory emotional self-efficacy, regulation strategy usage, and emotion outcomes, offers theoretical and practical utility within and beyond the sporting context. For example, Caprara, Vecchione, Barbaranelli, \& Alessandri (2013) found that regulatory emotional self-efficacy could improve emotional stability, a trait frequently associated with mental health (Kotov, Gamez, Schmidt, \& Watson, 2010). The aim of the present study was to examine the extent to which differences in athletes' own experienced and desired emotions were related to the frequency and perceived 
effectiveness of emotion regulation strategy use in the hour before sporting competition. We also examined the relationship regulatory emotional self-efficacy on the discrepancy between desired and experienced emotions. We hypothesized that those individuals with low regulatory emotional self-efficacy would demonstrate a greater discrepancy between experienced and desired emotions than those with high regulatory emotional self-efficacy. We replicated the examination of this hypothesis using participants' perceptions pertaining to a teammate (regulatory emotional other-efficacy).

\section{Method}

\subsection{Participants}

Participants were 114 team $/$ doubles athletes $\left(M_{\text {age }}=\right.$ 20.58 years, $S D=2.71$; men $n=97$, women $n=17$ ). All reported their main sport and responses included badminton, basketball, cricket, dancing, football, ice hockey, martial arts, netball, rock climbing, rugby, swimming, tennis, track and field, trampoline, triathlon, volleyball, and weight lifting. It should be noted that in sports such as triathlon or weightlifting which are in essence individual sports, it is still possible to compete as part of a team. For example, in triathlon, one person swims, one cycles and a third runs, or in track and field athletes were there is also a team competition.

Participants trained an average of 5.65 hours per week $(S D=3.26)$. Competitive performance levels were reported, including international $(3 \%)$, national $(9 \%)$, regional (35\%), university/college (16\%), club (21\%), and recreational (16\%). The number of years of experience in participants' respective main sport ranged from up to 6 months (1\%), 7-12 months (1\%), 1-2 years (5\%), 34 years $(6 \%), 5-6$ years $(6 \%), 7-8$ years $(11 \%), 9-10$ years $(12 \%)$, to over 10 years $(58 \%)$.

\subsection{Measures}

\subsubsection{Experienced and desired emotions}

Emotions were assessed using items taken from the UWIST Mood Adjective Checklist (UMACL; Matthews, Jones, \& Chamberlain, 1990), and the Brunel Mood Scale (BRUMS; Terry, Lane, Lane, \& Keohane, 1999). Single item adjectives are not useful ways to distinguish mood from emotion. As such, participants were asked to rate the levels of emotions (i.e., happy, angry, calm, downhearted, energetic, still, sluggish, enthusiastic, anxious) they experienced and desired to experience in relation to a competitive match that took place over the previous week. The reference to a specific event indicates that the term emotion is consistent with theoretical definitions (Beedie, Terry, \& Lane, 2005; Parkinson, et al., 1996) and previous measures (Beedie, Terry, \& Lane, 2011). This allowed an analysis of nine emotions representing the respective quadrants of the circumplex model of affect (Remington, Fabrigar, \& Visser, 2000). Enthusiastic and energetic represented pleasant high active emotions, anger and anxiety represented unpleasant high active emotions; happy, calm and still represented pleasant low active emotions, and downhearted and sluggish represented unpleasant low active emotions. Rather than attempt to create factor scores, results are displayed using single items as although they correlate, analysis of each item independently allows the researcher to see if data behaves the same way as other items in the higher-order scale. We should expect items to perform in a similar way if the same underlying scale is assessed. However, there is a great deal of research that argues for assessing emotions such as anger and anxiety independently (Lane \& Terry, 2000). Nevill, Duncan, \& Lane (2015) argued that examination psychological scales analyzing each item can be especially helpful for identifying items that behave differently to other items in the expected scale. When seen collectively, analysis of each item was argued to be the best way to show the results.

Participants were asked: "In the hour before the competitive performance you have identified how did you feel?'. They were also asked to report "In the hour before the competitive performance you have identified how did you want to feel?'. Participants rated emotion using a 5point scale ranging from 0 (not at all) to 4 (extremely) for each emotion. The perceived desired and actual emotions of a chosen teammate were likewise rated. The period of one-hour before performance was selected as this is the standard time to assess pre-competitive sport emotions (see Martens, Vealey, Burton, Bump, \& Smith, 1990), though it should be noted that precompetitive emotions can extend beyond this time frame (Cerin, Szabo, Hunt, \& Williams, 2000).

It is important to acknowledge that retrospective measures of emotion have limited accuracy, explained variously as resulting from faulty or incomplete encoding, memory decay, distorted recollections, or ambient mood (Parrott \& Sabini, 1990; Thomas \& Diener, 1990). As such, retrospective reports should not be treated as equivalent to measures taken with greater temporal proximity to the experience of interest. For the purpose of the present study, it was stipulated that the competitive event around which recall took place should occur within the previous week, this was in an attempt to attenuate the limitations of recall. This recall timeframe was deemed suitable when examining the general proximity of experienced emotions to desired emotions in a competitive sporting context.

\subsubsection{Regulatory emotional self-efficacy}

Following Bandura's (1997) recommendations for confidence estimates to be expressed on a percentage rating scale of $1-100 \%$, we asked participants: "On a scale of 1 to $100 \%$ where $1=$ "no confidence" and $100=$ "total confidence," how confident were you that you could change your emotions in the ways that you wanted to in the hour before competition?" Participants also provided ratings for confidence of being able to alter the chosen teammate's emotions (regulatory emotional other-efficacy). 


\subsubsection{Emotion regulation strategies}

Participants were asked to describe any strategies they used in the hour before competition to influence their own emotions. Specifically, they were asked; "In relation to how you felt before the competitive performance you have identified, what strategies did you use to influence the way you were feeling? It does not matter whether the strategies worked or not, please simply indicate those you used." Participants provided open-ended responses using as many words as they required.

Whilst measures of intra-personal emotion regulation strategies do exist (e.g., the Emotion Regulation Questionnaire; Gross \& John, 2003), such measures use a limited list of researcher-generated strategies. In order to capture and reflect a wider range of intra- and interpersonal emotion regulation strategies as used by participants, an open-ended approach was utilised whereby participants self-identified the range of strategies used. Participants were asked to indicate which of the nine emotions each strategy targeted, whether the intention was to increase, decrease or maintain that emotion, how effective the strategy was $(1=$ "not at all" to $7=$ "very effective"), and how frequently they used the strategy ( $1=$ "not at all" to $7=$ "a great deal"). Having done this, participants followed the same procedure to describe and rate each strategy used to influence the emotions of their chosen teammate. An acknowledged limitation is that rating another person's emotions is a difficult and complex task. Notwithstanding that emotions are inherently covert, there are multiple decisions on who to select. This is especially more difficult when there are multiple people and interaction among team members is limited. We recognize that this is a limitation of the present study. We emphasize that our study assesses perceptions of emotions in others, and these perceptions might not be close to how she or he perceived they were feeling.

\subsection{Procedure}

Following institutional ethical approval of the study, a convenience sample of team or doubles sport participants was recruited through university sport and exercise science classes. We explained the procedures to the participants and obtained written consent. Participants then completed the measures during university class time.

\subsection{Data analysis}

The differences between experienced and ideal emotions demonstrated large effect sizes, indicating sizeable discrepancies between experienced and ideal emotions. A primary study aim was to assess the extent to which such discrepancies were associated with emotion regulation. To overcome differences in the direction of emotion regulation (i.e., strategies being used to either increase, decrease, or maintain target emotions), we squared the differences between experienced and ideal emotions for self and other separately and then calculated the sum of these differences. We standardized the sum of emotion regulation differences, and placed participants into one of three groups representing their respective proximity to their ideal emotions: participants with a standardized score $<-1 S D$ were classified as scoring "very close" to ideal emotions; participants scoring within $1 S D$ (positive or negative), were classified as scoring "close" to their ideal emotions; and participants scoring $>1 S D$ were classified as scoring "far" from their ideal emotions. Pertaining to intra-and interpersonal emotion regulation strategies, all four authors independently read through the athletes' responses several times to familiarise themselves with the data. Text codes were generated by highlighting words and phrases from the responses that seemed to exemplify an emotion regulation strategy (Hsieh \& Shannon, 2005). The authors defined as many codes as they believed necessary to describe all aspects of the data (Elo \& Kyngäs, 2007). Codes were subsequently compared and revised in a series of meetings between the authors. There was a high degree of consensus during data coding, likely the result of participant responses being comprised mostly of short single-sentence statements rather than in-depth paragraphs. Once consensus regarding the codes was achieved, participants' statements were sorted into strategies based on links and relationships that seemed apparent between them, resulting in the organisation of the data into meaningful clusters (Elo \& Kyngäs, 2007). To further improve the trustworthiness of our analysis, we provide sufficient verbatim examples in the text of the Results section and in Tables 5 and 6 (Hsieh \& Shannon, 2005; Morse \& Field, 1995).

\section{Results}

MANOVA results revealed significant differences between experienced and desired emotions for self (Wilks' Lambda ${ }_{9,}{ }_{103}=0.30, p<0.001$, Partial $\mathrm{Eta}^{2}=0.70$; see Tab. 1) and teammate (Wilks' Lambda 9, $94=0.36$, $p<0.001$, Partial $\mathrm{Eta}^{2}=0.64$; see Tab. 2) with both demonstrating large multivariate effect sizes. Univariate analysis indicated that participants desired to feel significantly happier, calmer (low active pleasant emotions), more energetic and enthusiastic (high active pleasant emotions), and less downhearted, sluggish (low active unpleasant emotions) and anxious before competition. Participants reported wanting their teammates to experience the same emotion discrepancies as described for themselves, along with also desiring to experience significantly lower on stillness. In terms of the extent to which emotions performed in an expected way to their higher-order factor, anger performed differently to anxiety. However, when seen collectively, results indicate that desired emotions followed an hedonic model.

For athletes' own emotions, a comparison of emotion regulation effort variables by proximity to desired emotional state indicated a significant multivariate effect (Wilks' Lambda $6,216=0.89, p<0.04$, Partial Eta ${ }^{2}=$ $0.06)$. This low effect size indicates that participants furthest from their desired emotions demonstrated 
Table 1. Participants' experienced and ideal emotions.

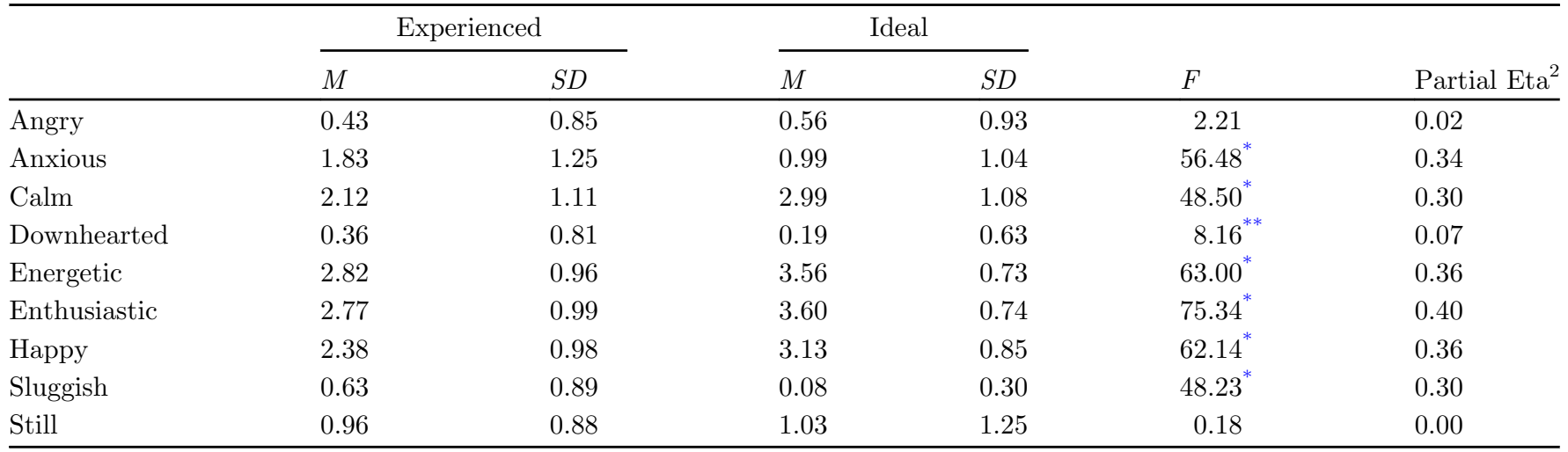

${ }^{*} p<0.001$
${ }^{* *} p<0.01$

Table 2. Participants' perceptions of teammate's experienced and ideal emotions.

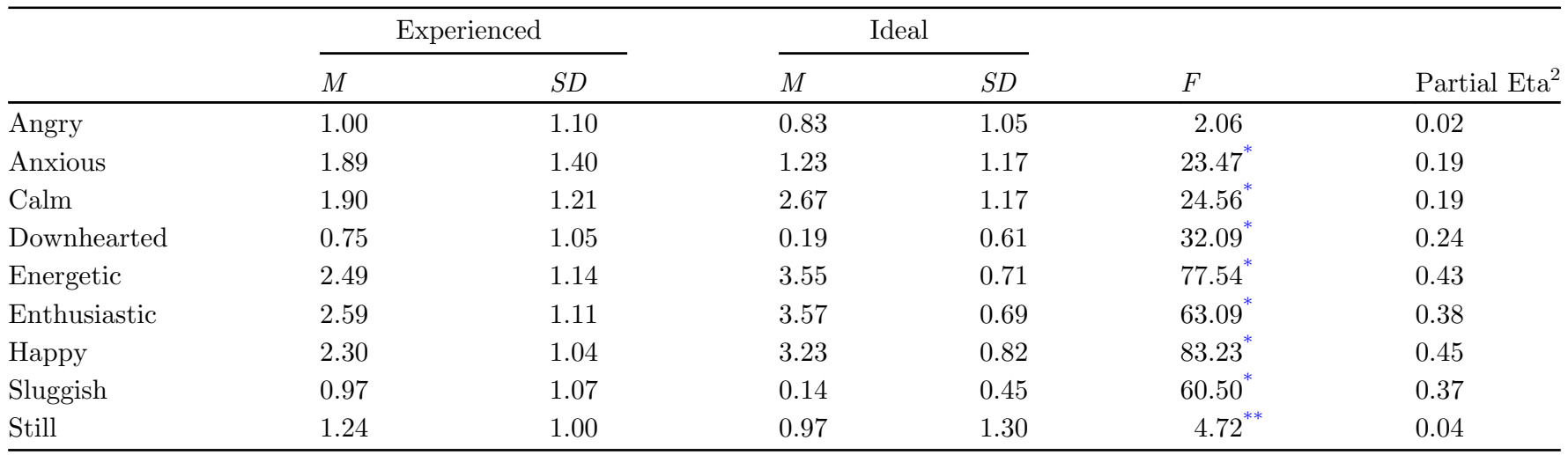

${ }_{* *}^{*} p<0.001$

$p<0.05$

significantly lower self-efficacy to regulate their emotions than participants who were closer to their desired state (see Tab. 3). Thus, we accept the hypothesis that individuals with low regulatory emotional self-efficacy will demonstrate a greater discrepancy between experienced and desired emotions than those with high regulatory emotional self-efficacy.

Analyzing the ratings provided for teammates, a comparison of emotion regulation variables by proximity to desired emotional state revealed a non-significant effect with small effect size (Wilks' Lambda $6, \quad{ }_{176}=0.81$, $p=0.22$, Partial $\left.\mathrm{Eta}^{2}=005\right)$. We reject the hypothesis that individuals with low regulatory emotional otherefficacy would perceive a greater discrepancy between the experienced and desired emotions of others, than those with high regulatory emotional other-efficacy.

We investigated the relationship between regulatory emotional self-efficacy and the frequency and effectiveness of strategy use, and the extent to which the proximity to desired emotions (the covariate) influence this relationship. The results support acceptance of the hypothesised association between regulatory emotional self-efficacy and emotions state of self, but not for others. Analyzing participants data for themselves, a multivariate analysis of covariance (MANCOVA) revealed significant effects for self-efficacy to change emotions (Wilks' Lambda 2, ${ }_{106}=0.84, p<0.001$, Partial $\mathrm{Eta}^{2}=0.16$ ) albeit with a weak effect size. There was with no significant effect for proximity to desired emotions (Wilks' Lambda 4 , ${ }_{212}=0.99, p=0.91$, Partial $\left.\mathrm{Eta}^{2}=0.00\right)$, and no interaction effect (Wilks' Lambda $4,212=0.84, p=0.85$, Partial $\left.\mathrm{Eta}^{2}=0.01\right)$. Univariate analyses indicated significant differences for effectiveness $(F=21.08, p<0.001$, Partial $\left.\mathrm{Eta}^{2}=0.15\right)$ and frequency $(F=7.68, p=0.01$, Partial $\left.\mathrm{Eta}^{2}=0.07\right)$ of strategy use, with small effects in magnitude.

Concerning a teammate's emotions, a MANCOVA for regulatory emotional other-efficacy to change the teammate's emotions, and proximity to desired emotions, indicated no significant effects for all three tests (perceived proximity to other's desired emotions: Wilks' Lambda 4 , $172=0.97, p=0.63$, Partial $\mathrm{Eta}^{2}=0.01$; confidence to change other's emotions: Wilks' Lambda ${ }_{2},{ }_{86}=0.94$, $p=0.07$, Partial Eta $\left.{ }^{2}=0.06\right)$, and no significant interaction effect (Wilks' Lambda $4,172=0.96, p=0.45$, Partial $\left.\mathrm{Eta}^{2}=0.02\right)$. Results indicated that self-efficacy to change 
Table 3. Experienced and ideal emotions discrepancies and emotion regulation variables.

\begin{tabular}{|c|c|c|c|c|c|c|c|c|}
\hline & \multicolumn{2}{|c|}{ Very close } & \multicolumn{2}{|c|}{ Close } & \multicolumn{2}{|c|}{ Far } & $F$ & Partial Eta ${ }^{2}$ \\
\hline \multicolumn{9}{|l|}{$\overline{\text { Self }}$} \\
\hline Perceived effectiveness & 5.35 & 1.21 & 5.07 & 0.91 & 4.88 & 1.29 & 1.56 & 0.03 \\
\hline Strategy frequency & 5.54 & 1.45 & 5.35 & 1.21 & 5.24 & 1.56 & 0.41 & 0.01 \\
\hline Perceived effectiveness & 5.03 & 1.16 & 5.00 & 1.27 & 5.26 & 1.22 & 0.43 & 0.01 \\
\hline Strategy frequency & 5.06 & 1.24 & 4.82 & 1.10 & 5.51 & 1.44 & 2.20 & 0.05 \\
\hline
\end{tabular}

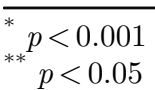

Table 4. Correlational relationships between emotion regulation variables for self and teammate.

\begin{tabular}{|c|c|c|c|}
\hline & $\begin{array}{l}\text { Regulatory emotional } \\
\text { self-efficacy }\end{array}$ & $\begin{array}{l}\text { Strategy } \\
\text { effectiveness }\end{array}$ & $\begin{array}{l}\text { Frequency of } \\
\text { strategy use }\end{array}$ \\
\hline \multicolumn{4}{|l|}{ Self } \\
\hline Regulatory emotional self-efficacy & 1.00 & $0.41^{*}$ & $0.26^{*}$ \\
\hline Perceived effectiveness & & 1.00 & $0.44^{*}$ \\
\hline Strategy frequency & & & 1.00 \\
\hline \multicolumn{4}{|l|}{ Teammate } \\
\hline Regulatory emotional other-efficacy & 1.00 & 0.18 & $0.30^{*}$ \\
\hline Perceived effectiveness & & 1.00 & $0.44^{*}$ \\
\hline Strategy frequency & & & 1.00 \\
\hline
\end{tabular}

* $p<0.05$

one's own emotions correlated significantly with perceived effectiveness and frequency of strategy use; the higher the individual rates their perceived self-efficacy to regulate their emotions, the more frequently they will use a strategy, and the more it is perceived to be effective. A similar trend was found for variables associated with interpersonal emotion regulation with the exception that confidence to change emotions was not significantly related to strategy effectiveness (see Tab. 4).

When asked to describe intrapersonal emotion regulation strategies used in the hour before competition, 268 data entries were provided. Eighteen of these entries were discarded because they did not identify a specific strategy (e.g., "I was able to remain calm"). The remaining 250 entries were classified under 14 broad strategy types, with the frequency of citations and exemplary quotes provided in Table 5. Overall, intrapersonal strategies were typically intended to increase energy (the focus of $21 \%$ of strategies cited), calmness (21\%), and enthusiasm (20\%), or to reduce anxiety (18\%). Participants reported 185 interpersonal strategies (18 removed) classified under 15 broad strategy types. The citation frequencies and exemplary quotes are provided in Table 6. Interpersonal emotion regulation strategies were intended to increase happiness $(20 \%)$, calmness $(17 \%)$, enthusiasm $(17 \%)$, and energy (14\%), or to reduce anxiety (14\%). The focus of emotion regulation was similar for self and other; both in terms of the emotions targeted (with the exception of additionally seeking to increase happiness in others, and a less prominent focus on increasing others' energy), and the strategies used to alter emotions of self and other.

\section{Discussion}

The present study examined athletes' ratings of their experienced and desired emotions in the hour before competing, and their perceptions of a chosen teammate. We analysed how discrepancies between experienced and desired emotions related to regulatory emotional selfefficacy, perceived strategy effectiveness, and usage frequency. Athletes reported large discrepancies between experienced and desired emotions for both themselves and for a teammate. According to the desired affective states for self and teammate, participants intended to increase pleasant emotions such as energetic and excited and low active pleasant emotions such as calm and happy. Participants intended to reduce the intensity of low activation unpleasant emotions such as depressed and sluggish (see Tabs. 1 and 2). Although the desire to increase hedonically pleasant emotions is consistent with 
Table 5. Intrapersonal emotion regulation strategy types $(n=250)$.

\begin{tabular}{|c|c|c|}
\hline Strategy & Frequency & Quotes \\
\hline Music & 48 & "I listen to upbeat but nice music to keep my anger low and save for the game." \\
\hline Visualization/rehearsal & 42 & "Visualizing positive moves I can make in the game, i.e., take on a defender." \\
\hline Interactions with others & 34 & "Interact with my teammates." \\
\hline Self-talk & 26 & $\begin{array}{l}\text { "Used self-talk, psyching myself up to increase anger levels. Telling myself I } \\
\text { need to get angry." }\end{array}$ \\
\hline Solitude & 9 & "Alone time to concentrate on task in hand." \\
\hline Reappraisals & 9 & "Treating the match as if it is a cup final so I am fully switched on." \\
\hline Consumption of food or drink & 8 & $\begin{array}{l}\text { "Eating good tasty meal before the game to get rid of hunger and increase } \\
\text { happiness." }\end{array}$ \\
\hline Recollecting past events & 8 & "Think of previous good performance." \\
\hline Positive thinking & 5 & "Use quotes from experienced people to bring to mind good emotions." \\
\hline Self-care & 1 & $\begin{array}{l}\text { "Have a morning wash freshens me up to feel more awake and ready. Feel } \\
\text { clean." }\end{array}$ \\
\hline
\end{tabular}

Table 6. Interpersonal emotion regulation strategy types $(n=167)$.

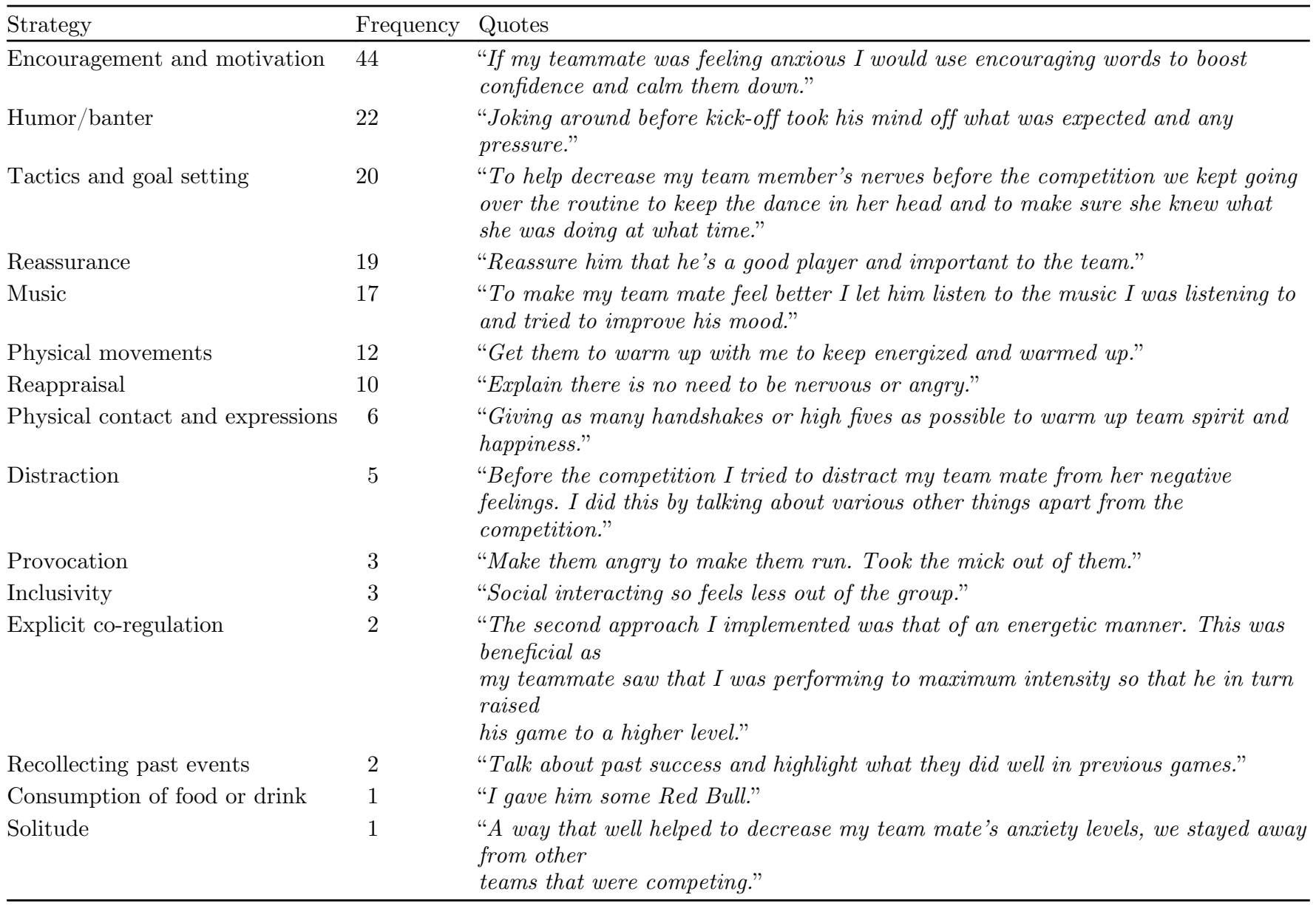


past findings and theory (e.g., Tamir, 2015), it is also important to note that studies have documented athletes' attempts to intensify high activation unpleasant emotions, such as anger and anxiety, due to their perceived functional role in facilitating performance (Hanin, 2007; Lane, Beedie, Devonport, \& Stanley, 2011; Robazza, et al., 2004). In the present study, we found no significant differences for experienced and desired ratings for anger. This may be because the analyses of aggregated scores across the sample negated individual response tendencies (i.e., some athletes may have been seeking to increase anger whilst others aimed at reducing anger). In the present study, we examined each emotion independently and although anger and anxiety inter-correlated, caution is urged regarding grouping them into a general unpleasant high-active emotion concept. A great deal of research in sport has forwarded arguments for investigating discrete emotions independently with a view to examine possible interactions among them (Lane \& Terry, 2000).

Future research should account for hedonic (for pleasure) and instrumental (purposeful relative to performance) motives (Tamir, 2009), as potentially competing goals for emotion regulation. Different motives for emotion regulation may negate individual response tendencies as described above. When examining the intrapersonal and interpersonal emotion regulation strategies identified respectively in Tables 5 and 6 , qualitative data evidence instrumental emotion regulation for the self and others. For example, "I listen to upbeat but nice music to keep my anger low and save for the game." (intrapersonal emotion regulation), or "Make them angry to make them run. Took the mick out of them." (interpersonal emotion regulation).

Whilst there was possible evidence of hedonic motives for regulating the emotions of others (e.g., "Social interacting so feels less out of the group"), such interpersonal emotion regulation may also act as instrumental regulation (Lane, et al., 2011). The findings add to the growing literature on individual differences that influence emotion regulation (e.g., Gross \& John, 2003; Tamir, et al., 2007). In the current study, participants reported large discrepancies between their experienced and desired levels of a range of emotions before competing. Drawing on self-regulation theory (Carver \& Scheier, 1990), individuals will attempt to alter their emotions if they experience a sufficient gap between their current and desired emotional states. Crucially however, our data suggested that it might not be the size of the discrepancy between their experienced and desired emotions that determines emotion regulation strategy use; one's confidence in regulating emotions seems to be a key driver in frequency of strategy use and their perceived effectiveness. Irrespective of how far athletes were from their desired emotions, those who felt confident in managing their emotions also reported emotion regulation strategies to be used more frequently and to be more effective. Conversely, it seems that those who lack confidence in regulating their emotions use strategies less frequently, and also rate those strategies as less effective. While it might be intuitive that low self-efficacy relates to infrequent strategy usage, research has also purported the opposite. Devonport \& Lane (2014) demonstrated in a longitudinal intervention that high emotional-efficacy associated with infrequent strategy usage whereby effective emotion regulation negates any need for further use. Further research is warranted in order to unpack these relationships.

Although regulatory emotional self-efficacy seems to be an important factor in regulating one's own emotions, a different pattern of responses emerged for regulating others' emotions. When attempting interpersonal emotion regulation before competition, participants' highest selfefficacy ratings occurred when the difference between observed and desired emotions in a teammate was the largest. The further participants perceived their teammate to be from their desired emotions, the more confident participants were in being able to alter that person's emotions. Clearly, individuals have greater access to their own emotional states than those of others, and when making estimates of others' experienced and desired emotions they have to make use of particular kinds of available information, such as overt emotional expressions or behaviors (Furley \& Schweizer, 2014), emotional empathy (Sevdalis \& Raab, 2014), or verbal inquiries as to how the teammate is feeling before attempting to regulate their emotions. Recent research has advocated for the use of video-assisted emotion recall whereby participants debrief performance videos to discuss currentdesired emotion discrepancies as well as emotion regulation strategies (e.g., Martinent, Ledos, Ferrand, Campo, \& Nicolas, 2015). We advocate for the continued examination of video-assisted recall methods to study emotions and emotion regulation in sport as it might provide a viable way for athletes to learn how to identify subtle emotional changes in their teammates (e.g., Campo, et al., 2016).

The challenge to perceive subtle changes in the emotions of others may help explain why the responses provided to describe the form and focus of strategies used to regulate others' emotions closely paralleled the form and focus of strategies participants used on themselves. It seems that participants presume strategies that are effective in changing their own emotions will be effective in changing others' emotions. Athletes conceivably believe that potential emotion antecedents, such as the perceived quality of opposition will have a similar effect on others' emotions as it does on themselves. Thus, strategies used to regulate one's own emotions are considered viable options for altering a teammate's emotions. An alternative explanation may be that individuals have observed, or believe that certain strategies (e.g., humor, playing loud music), when carried out in the presence of others, have an emotional impact on the other person via processes such as emotion contagion (Parkinson, 1996; Totterdell, 2000). As such, in using strategies such as humor, an athlete might be striving to concurrently regulate their own and others emotions. We recommend additional research is conducted to investigate and clarify these possibilities and the relationship between intra- and interpersonal emotion regulation in sport. 
Our findings offer implications for applied interventions targeting intra- and interpersonal emotion regulation in sport. Self-reported beliefs in emotional intelligence have been found to be related to the frequency of psychological skill use (Lane, Thelwell, Lowther, \& Devonport, 2009). Since emotional intelligence and regulatory emotional self-efficacy are closely related concepts (Petrides, et al., 2007), our results add to such research by suggesting that if regulatory emotional selfefficacy is important in determining whether, or how, individuals will attempt to alter their emotions, regulatory emotional self-efficacy needs to be incorporated in future interventions. As found by Robazza et al. (2004), athletes can be provided with strategies to target the emotions they associate with their best performance, with concomitant benefits for emotional and performance outcomes. We propose that as well as teaching athletes emotion regulation strategies, potential gains might be enhanced by including techniques to build regulatory emotional selfefficacy that alter beliefs as to whether emotions are controllable (see also Tamir, et al., 2007). Further, based on our finding that athletes seem more confident at regulating others' emotions when the other is perceived as a long way from their desired state, it also seems that skills that enhance empathic accuracy would be an important addition in future applied interventions. Specifically, interventions that help athletes develop the ability to recognize, understand and help manage others' emotions would be an important contribution to performance training.

Despite yielding some useful insights on emotion regulation in sport, this study has several limitations that can be addressed in subsequent work to extend the current findings. A first limitation is that a range of sports was included. Sport psychologists have reflected on the nuances of different sports and how these influence the concomitant mental and emotional states experienced by participant athletes (Dosil, 2006). It is also possible that different sport subcultures have distinct rules governing which emotions are appropriate to express/display and regulate, or when this should occur (e.g., Friesen, et al., 2015). Future studies might examine target sports in detail to examine which emotions are experienced and/or desired the most, and how they in turn might influence emotion regulation strategy use. A second limitation was that the present study only considered the emotional outcomes of regulatory efforts; it did not consider the impact of emotion regulation on sports performance. One of the reasons athletes regulate emotions is because they expect there to be subsequent improvements to their respective performances (Lane, et al., 2012). Therefore, we recommend that performance variables are included in future research on emotion regulation in sport. Thirdly, by using a convenience sample from a university course, our participant sample had many more men than women, which could have affected our results given documented gender effects in emotion regulation (e.g., Webb, Miles, \& Sheeran, 2012). A fourth limitation pertains to the regulatory emotional self-efficacy scale. This was completed once in respect of self-efficacy for general emotion regulation. It is plausible that an athletes' confidence to change different discreet emotions might vary. For example, they could be very confident in their ability to change energetic as desired in the hour before competition, whereas they may not be confident in their ability to regulate anger as desired in the hour before competition. To account for this possibility, we recommend that in future research participants complete a regulatory emotional self-efficacy scale for each emotion assessed.

Extending the investigation to time frames beyond the hour before competing could further elucidate the relationships between emotion regulation strategy use and regulatory emotional self-efficacy. Longitudinal research would be especially timely to determine the situational variability of participants' experienced and desired emotions in different sport situations (e.g., training versus competition), or the role of regulatory emotional selfefficacy and strategy use in times of injury or team selection. Alternatively, experiences in sport versus other performance domains could be contrasted to determine the extent to which regulatory emotional self-efficacy might vary across situations (e.g., work, academia, performing arts contexts) wherein different goals or outcomes are being pursued or different profiles of emotions might be desired (Lane, Davis, \& Stanley, 2014). Longitudinal research would also permit the inclusion and analysis of outcome variables such as long-term sport participation, enjoyment, burnout, or performance.

In conclusion, we found overlap in the emotions targeted for self and others, and in the kinds of strategies used for regulating emotions. Self-efficacy to regulate emotions appears to be an individual difference variable which may be influential, particularly for managing one's own emotions. Further research is needed to understand the role of regulatory emotional self-efficacy in the management of emotions, including the management of others' emotions, and to test interventions seeking to enhance regulatory emotional self-efficacy.

\section{References}

Alessandri, G., Vecchione, M., \& Caprara, G.V. (2015). Assessment of regulatory emotional self-efficacy beliefs: A review of the status of the art and some suggestions to move the field forward. Journal of Psychoeducational Assessment, 33(1), 24-32. doi: 10.1177/0734282914550382.

Bandura, A. (1997). Self-efficacy: The exercise of control. New York, NY: W. H. Freeman and Company.

Barrett, L.F., \& Russell, J.A. (1999). The structure of current affect: Controversies and emerging consensus. Current Directions in Psychological Science, 8(1), 10-14. doi: 10.1111/1467-8721.00003.

Beedie, C.J., Terry, P.C., \& Lane, A.M. (2000). The profile of mood states and athletic performance: Two meta-analyses. Journal of Applied Sport Psychology, 12, 49-68. doi: 10.1080/ 10413200008404213.

Beedie, C., Terry, P., \& Lane, A. (2005). Distinctions between emotion and mood. Cognition \& Emotion, 19(6), 847-878. doi: 10.1080/02699930541000057. 
Beedie, C.J., Terry, P.C., Lane, A.M., \& Devonport, T.J. (2011). Differential assessment of emotions and moods: Development and validation of the Emotion and Mood Components of Anxiety Questionnaire. Personality and Individual Differences, 50(2), 228-233. doi: 10.1016/j.paid.2010.09.034.

Campo, M., Sanchez, X., Ferrand, C., Rosnet, E., Friesen, A., \& Lane, A.M. (2016). Interpersonal emotion regulation in team sport: Mechanisms and reasons to regulate teammates' emotions examined. International Journal of Sport and Exercise Psychology, 15, 379-394. doi: $10.1080 /$ 1612197X.2015.1114501.

Caprara, G., Vecchione, M., Barbaranelli, C., \& Alessandri, G. (2013). Emotional stability and affective self-regulatory efficacy beliefs: Proofs of integration between trait theory and social cognitive theory. European Journal of Personality, 27(2), 145-154. doi: 10.1002/per.1847.

Carver, C.S., \& Scheier, M.F. (1990). Origins and functions of positive and negative affect: A control-process view. Psychological Review, 97, 19-35. doi: 10.1037/0033-295X.97.1.19.

Cerin, E., Szabo, A., Hunt, N., \& Williams, C. (2000). Temporal patterning of competitive emotions: A critical review. Journal of Sports Sciences, 18, 605-626. doi: 10.1080/02640410050082314.

Cheshin, A., Heerdink, M.W., Kossakowski, J.J., \& Van Kleef, G.A. (2016). Pitching emotions: The interpersonal effects of emotions in professional baseball. Frontiers in Psychology, 7 , 178. doi: 10.3389/fpsyg.2016.00178.

Craft, L.L., Magyar, T.M., Becker, B.J., \& Feltz, D.L. (2003). The relationship between the Competitive State Anxiety Inventory-2 and sport performance: A meta-analysis. Journal of Sport and Exercise Psychology, 25, 44-65. doi: 10.1123/ jsep.25.1.44.

Devonport, T.J., \& Lane, A.M. (2014). Evaluation of a 12-month coping intervention intended to enhance future-oriented coping in goal-oriented domains. Journal of Clinical Sport Psychology, 8(1), 38-56. doi: 10.1123/jcsp.2014-0011.

Dosil, J. (Ed.). (2006). The sport psychologist's handbook: A guide for sport-specific performance enhancement. Chichester, UK: John Wiley and Sons.

Eisenberg, N., Spinrad, T.L., \& Smith, C.L. (2004). Emotionregulated regulation: Its conceptualization, relations to social functioning, and socialization. In P. Philippot \& R.S. Feldman (Eds.), The regulation of emotion (pp. 277-306). Mahwah, NJ: Lawrence Erlbaum Associates.

Elo, S., \& Kyngäs, H. (2007). The qualitative content analysis process. Journal of Advanced Nursing, 62, 107-115. doi: 10.1111/j.1365-2648.2007.04569.x.

Friesen, A.P., Lane, A.M., Devonport, T.J., Sellars, C.N., Stanley, D.N., \& Beedie, C.J. (2013). Emotion in sport: Considering interpersonal regulation strategies. International Review of Sport and Exercise Psychology, 6(1), 139-154. doi: 10.1080/1750984X.2012.742921.

Friesen, A.P., Devonport, T.J., Sellars, C.N., \& Lane, A.M. (2015). Examining interpersonal emotion regulation strategies and moderating factors in ice hockey. Athletic Insight, 7 (2), 143-160.

Friesen, A.P., Devonport, T.J., \& Lane, A.M. (2016). Beyond the technical: The role of emotion regulation in lacrosse officiating. Journal of Sports Sciences, 5(6), 579-586. doi: 0.1080/02640414.2016.1180419.

Furley, P., \& Schweizer, G. (2014). The expression of victory and loss: Estimating who's leading or trailing from nonverbal cues in sports. Journal of Nonverbal Behavior, 38(1), 13-29. doi: 10.1007/s10919-013-0168-7.

Gross, J.J., \& John, O.P. (2003). Individual differences in two emotion regulation processes: Implications for affect, relationships, and well-being. Journal of Personality and Social Psychology, 85, 348-362. doi: 10.1037/0022-3514.85.2.348.
Hanin, Y.L. (2007). Emotions in sport: Current issues and perspectives. In G. Tenenbaum \& R.C. Eklund (Eds.), Handbook of sport psychology (3rd ed.) (pp. 31-58). Hoboken, NJ: John Wiley and Sons.

Hanin, Y.L. (2010). Coping with anxiety in sport. In A. Nicholls (Ed.), Coping in sport: Theory, methods, and related constructs (pp. 159-175). New York: Nova Science.

Hanin, Y.L, \& Stambulova, N.B. (2002). Metaphoric description of performance states: An application of the IZOF model. The Sport Psychologist, 16, 396-415. doi: 10.1123/ tsp.16.4.396.

Hsieh, H.F., \& Shannon, S.E. (2005). Three approaches to qualitative content analysis. Qualitative Health Research, 15, 1277-1288. doi: 10.1177/1049732305276687.

Jokela, M., \& Hanin, Y.L. (1999). Does the Individual Zones of Optimal Functioning model discriminate between successful and less successful athletes: A meta-analysis. Journal of Sports Sciences, 17, 873-887. doi: 10.1080/026404199365434.

Kotov, R., Gamez, W., Schmidt, F., \& Watson, D. (2010). Linking "big" personality traits to anxiety, depressive, and substance use disorders: A meta-analysis. Psychological Bulletin, 136(5), 768-821. doi: 10.1037/a0020327.

Lane, A.M., Beedie, C.J., Devonport, T.J., \& Stanley, D.M. (2011). Instrumental emotion regulation in sport: Relationships between beliefs about emotion and emotion regulation strategies used by athletes. Scandinavian Journal of Medicine \& Science in Sports, 21(6), e445-e451. doi: 10.1111/j.16000838.2011.01364.x.

Lane, A.M., Beedie, C.J., Jones, M.V., Uphill, M., \& Devonport, T.J. (2012). The BASES expert statement on emotion regulation in sport. Journal of Sports Sciences, 30, 11891195. doi: 10.1080/02640414.2012.693621.

Lane, A., Davis, P., \& Stanley, D. (2014). Do emotion regulation intentions and strategies differ between situations? Current Advances in Psychology Research, 1(1), 26-32.

Lane, A.M., \& Terry, P.C. (2000). The nature of mood: Development of a conceptual model with a focus on depression. Journal of Applied Sport Psychology, 12(1), 1633. doi: 10.1080/10413200008404211.

Lane, A.M., \& Terry, P. (2016). Online mood profiling and selfregulation of affective responses. In R.J. Schinke, K.R., McGannon, \& B. Smith (Eds.), Routledge International Handbook of Sport Psychology (pp. 324-333). London: Routledge.

Lane, A.M., Thelwell, R., Lowther, J.P., \& Devonport, T. (2009). Relationships between emotional intelligence and psychological skills among athletes. Social Behaviour and Personality: An International Journal, 37, 195-202. doi: 10.2224/sbp.2009.37.2.195.

Matthews, G., Jones, D.M., \& Chamberlain, A.G. (1990). Refining the measurement of mood: The UWIST mood adjective checklist. British Journal of Psychology, 81(1), 1742. doi: 10.1111/j.2044-8295.1990.tb02343.x.

Martens, R., Vealey, R.S., Burton, D., Bump, L., \& Smith, D.E. (1990). Development and validation of the Competitive Sports Anxiety Inventory-2. In R. Martens, R.S. Vealey, \& D. Burton (Eds.), Competitive anxiety in sport (pp. 117-178). Champaign, IL: Human Kinetics.

Martinent, G., Ledos, S., Ferrand, C., Campo, M., \& Nicolas, M. (2015). Athletes' regulation of emotions experienced during competition: A naturalistic video-assisted study. Sport, Exercise, and Performance Psychology, 4(3), 188-205. doi: $10.1037 /$ spy0000037.

Matthews, G., Jones, D.M., \& Chamberlain, A.G. (1990). Refining the measurement of mood: The UWIST Mood Adjective Checklist. British Journal of Psychology, 81, 17-42. doi: 10.1111/j.2044-8295.1990.tb02343.x. 
Meyer, B.B., \& Fletcher, T.B. (2007). Emotional intelligence: A theoretical overview and implications for research and professional practice in sport psychology. Journal of Applied Sport Psychology, 19, 1-15. doi: 10.1080/10413200601102904.

Moll, T., Jordet, G., \& Pepping, G. (2010). Emotional contagion in soccer penalty shootouts: Celebration of individual success is associated with ultimate team success. Journal of Sports Sciences, 28, 983-992. doi: 10.1080/02640414.2010.484068.

Morse, J.M., \& Field, P.A. (1995). Qualitative research methods for health professionals (2nd ed.). Thousand Oaks, CA: Sage.

Nevill, A.M., Lane, A.M., \& Duncan, M.J. (2015). Are the Multidimensional Body Self-Relations Questionnaire Scales stable or transient? Journal of Sports Sciences, 33(18), 18811889. doi: 10.1080/02640414.2015.1018930.

Palmateer, T., \& Tamminen, K. (2018). A Case study of interpersonal emotion regulation within a varsity volleyball team. Journal of Applied Sport Psychology, 30, 321-340, doi: 10.1080/10413200.2017.1367335.

Parkinson, B. (1996). Emotions are social. British Journal of Psychology, 87, 663-683. doi: 10.1111/j.2044-8295.1996. tb02615.x.

Parkinson, B., Totterdell, P., Briner, R.B., \& Reynolds, S. (1996). Changing moods: The psychology of mood and mood regulation. London: Longman.

Parrott, W.G., \& Sabini, J. (1990). Moods and memory under natural conditions: Evidence for mood congruent recall. Journal of Personality and Social Psychology, 59, 321-336. doi: 10.1037/0022-3514.59.2.321.

Petrides, K.V., Furnham, A., \& Mavroveli, S. (2007). Trait emotional intelligence: Moving forward in the field of EI. In G. Matthews, M. Zeidner, \& R.D. Roberts (Eds.), The science of emotional intelligence: Knowns and unknowns. Series in affective science (pp. 151-166). Oxford, UK: Oxford University Press.

Remington, N.A., Fabrigar, L.R., \& Visser, P.S. (2000). Reexamining the circumplex model of affect. Journal of Personality and Social Psychology, 79, 286-300. doi: 10.1037//0022-3514.79.2.286.

Robazza, C., Pellizzari, M., \& Hanin, Y. (2004). Emotion selfregulation and athletic performance: An application of the IZOF model. Psychology of Sport and Exercise, 5, 379-404. doi: $10.1177 / 0145445503261174$.

Sevdalis, V., \& Raab, M. (2014). Empathy in sports, exercise, and the performing arts. Psychology of Sport and Exercise, 15 (2), 173-179. doi: 10.1016/j.psychsport.2013.10.013.
Stanley, D.M., Beedie, C.J., Lane, A.M., Friesen, A.P., \& Devonport, T.J. (2012). Emotion regulation strategies used by runners prior to training and competition. International Journal of Sport and Exercise Psychology, 10, 159-171. doi: 10.1080/1612197X.2012.671910.

Tamir, M. (2009). What do people want to feel and why? Pleasure and utility in emotion regulation. Current Directions in Psychological Science, 18(2), 101-105. doi: 10.1111/ j.1467-8721.2009.01617.x.

Tamir, M. (2015). Why do people regulate their emotions? A taxonomy of motives in emotion regulation. Personality and Social Psychology Review, 20(3), 199-222. doi: 10.1177/ 1088868315586325.

Tamir, M., John, O.P., Srivastava, S., \& Gross, J.J. (2007). Implicit theories of emotion: Affective and social outcomes across a major life transition. Journal of Personality and Social Psychology, 92, 731-744. doi: 10.1037/00223514.92.4.731.

Tamminen, K.A., \& Crocker, P.R.E. (2013). "I control my own emotions for the sake of the team": Emotional self-regulation and interpersonal emotion regulation among female highperformance curlers. Psychology of Sport and Exercise, 14(5), 737-747. doi: 10.1016/j.psychsport.2013.05.002.

Terry, P.C., Lane, A.M., Lane, H.J., \& Keohane, L. (1999). Development and validation of a mood measure for adolescents. Journal of Sports Sciences, 17, 861-872. doi: $10.1080 / 026404199365425$.

Thomas, D.L., \& Diener, E. (1990). Memory accuracy in the recall of emotions. Journal of Personality and Social Psychology, 59(2), 291-297. doi: 10.1037/0022-3514.59.2.291.

Totterdell, P. (2000). Catching moods and hitting runs: Mood linkage and subjective performance in professional sport teams. Journal of Applied Psychology, 85, 848-859. doi: 10.1037/0021-9010.85.6.848.

Totterdell, P., \& Leach, D. (2001). Negative mood regulation expectancies and sports performance: An investigation involving professional cricketers. Psychology of Sport and Exercise, 2, 249-265. doi: 10.1016/S1469-0292(01)00016-4.

van Kleef, G.A., Cheshin, A., Fischer, A.H., \& Schneider, I.K. (2016). Editorial: The Social Nature of Emotions. Frontiers in Psychology, 7. doi: 10.3389/fpsyg.2016.00896.

Webb, T.L., Miles, E., \& Sheeran, P. (2012). Dealing with feeling: A meta-analysis of the effectiveness of strategies derived from the process model of emotion regulation. Psychological Bulletin, 138, 775-808. doi: 10.1037/a0027600.

Cite this article as: Friesen A, Stanley D, Devonport T, \& Lane AM (2019) Regulating own and teammates' emotions prior to competition. Mov Sport Sci/Sci Mot, 105, 5-15 